\title{
Gehörgangsekzem
}

\section{Ernsthaftes Behandlungsproblem oder Bagatellerkrankung?}

\author{
Dieter Leithäuser
}

\section{Die Behandlung von entzündlichen Veränderungen von Kutis und Subkutis des äußeren Gehörgangs gehört zu den häufigsten Aufgaben in der Praxis des niedergelassenen HNO-Arztes.}

A uslösend für ein Gehörgangsekzem (Abb 1 und 2) ist häufig eine vom Patienten durchgeführte, fast zwanghaft ausgeübte Selbstreinigung des Gehörgangs mit Wattestäbchen (Abb. 3). Auch ein ständiger Kontakt des Gehörgangs mit Wasser kann einem Ekzem den Boden bereiten.

Das Erscheinungsbild der Gehörgangsreizung und insbesondere spezieller Ekzembildungen ist sehr wechselhaft und spielt sich an den verschiedenen Abschnitten der Gehörgangshaut ab. Eine wichtige Rolle spielen Veränderungen der Talgdrüsen (Abb 4). Geprägt sind Ekzeme durch einen hartnäckigen Juckreiz. Erst später treten entzündliche Veränderungen von Kutis und Subkutis in Erscheinung. Diese Entzündungsformen führen zu den bekannten Formen einer bakteriellen oder virogenen Otitis externa.

Allen Entzündungsformen im Gehörgangs- und Trommelfellbereich ist ein rascher Beginn mit einer ausgeprägten Schmerzhaftigkeit ohne Schmerzpausen gemeinsam. Dieses Phänomen ist durch den klinischen Befund eines ausgeprägten entzündlichen Ödems der Gehörgangshaut ohne Ausweichmöglichkeit in ein subkutanes Fettgewebe begründet.
Die Behandlung des Gehörgangsekzems besteht hauptsächlich in einer nicht-aggressiven Hygiene des Gehörgangs, Vermeidung von ständigem Wasserkontakt und therapeutische Einflussnahme auf die Talgdrüsen. Bewährt haben sich hierzu harnstoffhaltige Salben und Lotionen. Ein Beispiel ist die Rezeptur von Luckhaupt, Dortmund:

Rp.:

Urea pura 2,0

Ungt. Emulsif. Aq. Ad 100,0

S. $2 \%$ Harnstoffcreme

Mittlerweile sind aber auch Fertigpräparate auf dem Markt, die einen günstigen Einfluss auf die ekzemauslösenden Talgdrüsen nehmen können.

\section{Dr. med. Dieter Leithäuser}

Zum Diemelblick 1

34414 Warburg
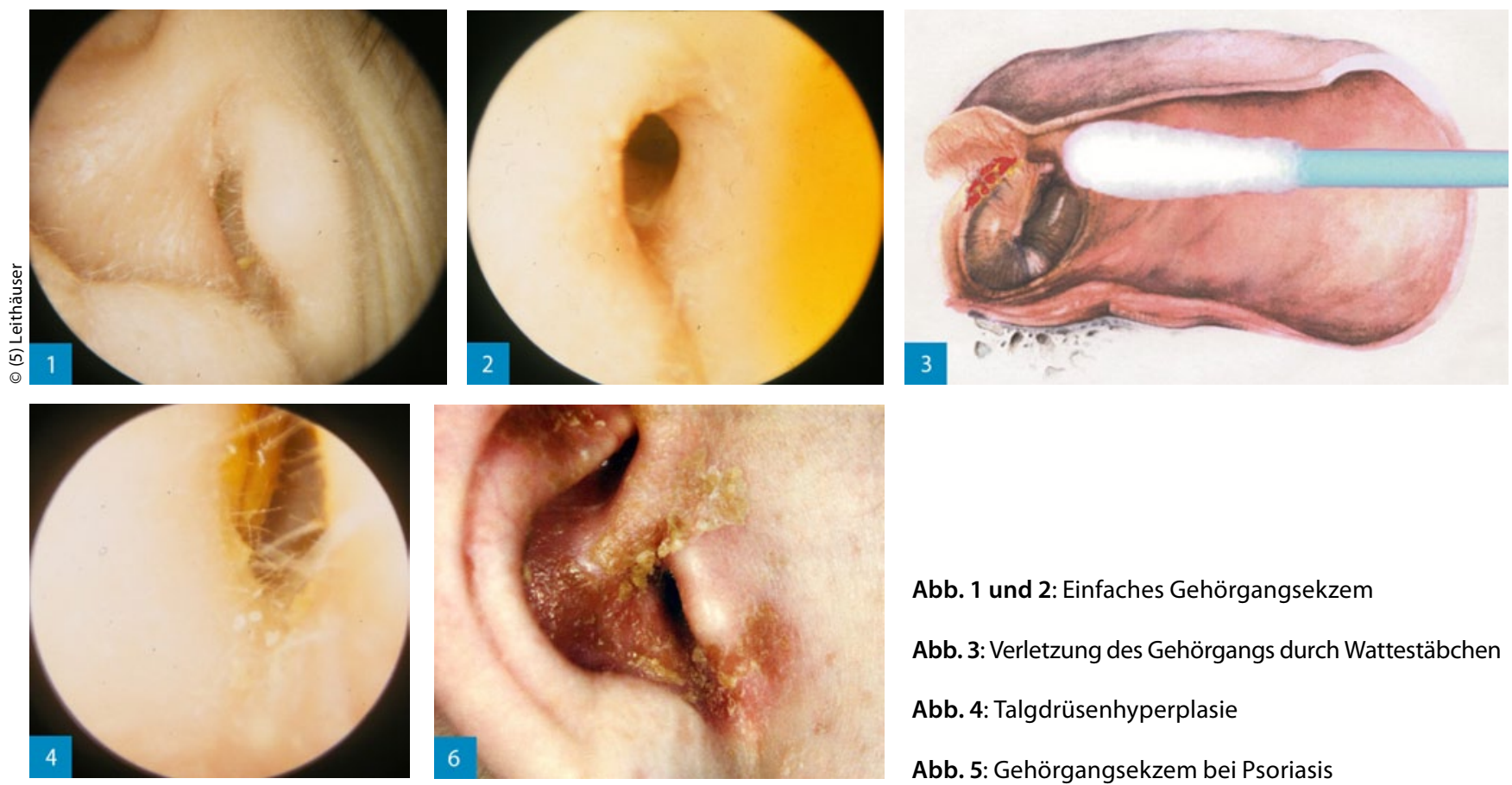

Abb. 1 und 2: Einfaches Gehörgangsekzem

Abb. 3: Verletzung des Gehörgangs durch Wattestäbchen

Abb. 4: Talgdrüsenhyperplasie

Abb. 5: Gehörgangsekzem bei Psoriasis 